\title{
Impact of independent and non-independent parameters on various elements' rejection by nanofiltration employed in groundwater treatment
}

\author{
Mohammad Mahdi Emamjomeh $^{1} \cdot$ Hossein Torabi $^{2} \cdot$ Milad Mousazadeh $^{1,2} \cdot$ Mohammad Hossein Alijani $^{3} \cdot$ \\ Fariba Gohari ${ }^{4}$
}

Received: 31 May 2018 / Accepted: 28 March 2019 / Published online: 22 April 2019

(c) The Author(s) 2019

\begin{abstract}
Nanofiltration is one of the widely used robust methods in water sweetening throughout the world. This work highlights the comparison of the impact of independent and non-independent parameters on element rejection to treat groundwater of a region located in Qazvin province, Iran. A pilot-scale FILMTEC-NF90-4040 nanofilter membrane was applied. Samples were collected from three various wells and the volume of $50 \mathrm{cc}$ was tested, each of which was tested three times, and then cations and anions were measured in raw water and treated water by ion chromatography. The data collection and operation of the system was performed by the 761 compact IC version 1.1 software where statistical analyses were performed with SPSS, version 19. Results showed that the degradation efficiency of divalent ions was greater than that of monovalent cations. The content of ion rejection in the nanofilter membrane was not an independent phenomenon. For instance, the results revealed that the presence of high magnesium ion is very effective in disposing sodium ion. At the same time, the rejection rate of ions does not always follow the Van't Hoff series. Optimal pressure was determined to be 10 bar.
\end{abstract}

Keywords Nanofiltration $\cdot$ Groundwater $\cdot$ Desalination $\cdot$ Ion rejection

\section{Introduction}

Freshwater resources have been dramatically decreasing in recent years and also in the perspective of the coming years (Cominelli et al. 2009). On the other hand, groundwater is imposed to get salty which is not directly potable (Song et al. 2016). This is to the extent that in many parts of the world, water available to use is salty and many people across the world are deprived of having access to freshwater resources (Jury and Vaux 2007; Pantelides 2013; Song

Hossein Torabi

hossein.torabi2@gmail.com

1 Social Determinant of Health Research Center, Qazvin University of Medical Sciences, Qazvin, Iran

2 Student Research Committee, Qazvin University of Medical Sciences, Qazvin, Iran

3 Research Center of Qazvin Water and Wastewater Company, Qazvin, Iran

4 Department of Civil and Environmental Engineering, University of Western Ontario, London, Canada et al. 2016). Among the various processes of water sweetening, membrane operations such as reverse osmosis (RO) and nanofiltration (NF) are more popular for a variety of reasons (Nicolaisen 2003; Galanakis et al. 2012). Nanofiltration is one of the significant applications of nanotechnology that allows nanoscale particles to be separated from the water and produce refined water in bulk. In this method, the existing membrane separates the two homogeneous phases, and by preventing the passage of impurities, it selectively purifies the water (Mayer et al. 2010; Gehrke et al. 2015; Emamjomeh et al. 2018). The separation mechanism in the nanofilter generally involves the size of the molecules as well as the electrical response between the surface of the membrane and the ions in the feed (Song et al. 2016).

Nanofiltration removes a number of healthy elements from water, in addition to the harmful elements. The removal of these elements, such as calcium $\left(\mathrm{Ca}^{2+}\right)$ and magnesium $\left(\mathrm{Mg}^{2+}\right)$, can actually make water unhealthy. On the other hand, the mentioned elements and other multivalent cations cause water hardness. Having too soft water is problematic too; in addition, soft water on the other hand is corrosive. This lowers the water quality; consequently, the quality

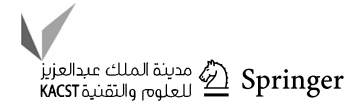


requirements at the consumer's end might not be met anymore (Gray 2008; Mohammadi et al. 2018; Honarbakhsh 2019). World Health Organization (WHO) suggested that the permissible range of sodium, magnesium, potassium, calcium, sulfate, chloride and nitrate contents in drinking water is about $200 \mathrm{mg} / \mathrm{L}, 50 \mathrm{mg} / \mathrm{L}, 12 \mathrm{mg} / \mathrm{L}, 75 \mathrm{mg} / \mathrm{L}, 250 \mathrm{mg} / \mathrm{L}$, $300 \mathrm{mg} / \mathrm{L}$ and $5 \mathrm{mg} / \mathrm{L}$, respectively (WHO 2011). Given that fifty percent of the groundwater and seventy-eight percent of the river water in urban areas is non-drinkable, applications of this technology for water treatment has gained a lot of attention. Research in China has shown that with the use of water from nanofilters for a long time, the prevalence of cardiovascular and cancerous diseases has been reduced by forty and two percent, respectively (Wimalawansa 2013; Najafpoor et al. 2014; Honarbakhsh 2019). RO filters remove all salts dissolved in water, while NF filters, or nanofilters, create a selective mode of absorption of materials, giving us the right to choose the desired quality of water (Dach 2008). Several studies have proved that nanofiltration is even effective at low pressures; hence, it can be superior to reverse osmosis in similar conditions (Vaseghi et al. 2016; Talaeipour et al. 2017).

One of the most important identified foulants found in surface water filtration is natural organic matters (NOMs). NOMs are widely recognized as the major foulants to reduce the permeate flux in membrane filtration (Xiao et al. 2012). Nanofilter membranes have no surface transition rate between $\mathrm{RO}$ and ultrafiltration so that this value is about $98 \%$ for bivalent ions and lower for monovalent ions (Alkhatim et al. 1998; AlTaee and Sharif 2011). A lot of studies have also been done on the performance of the nanofilter for water softening. In 2011, Mortazavi and colleagues (Mortazavi and Mousavi 2012) conducted a study to investigate the performance of nanofilter in removing iron from groundwater, which resulted in high efficiency of $90 \%$ directly related to increasing pressure.

The study conducted by Chakrabortty et al. (2013) which investigated the rejection of fluoride from groundwater sources by the process of nanofiltration resulted in the rejection of more than $98 \%$ fluoride at a pressure of $144 \mathrm{~kg} / \mathrm{cm}^{2}$ and $\mathrm{pH}$ of 10.01. Aroji et al. (2016) evaluated the efficiency of nanofiltration in domestic water treatment and observed the following system efficiency in removing electrical conductivity $(98.47 \%)$, total soluble solids $(98.95 \%)$, total hardness (98.74\%), calcium (98.5\%), magnesium (99.13\%), chloride $(96.46 \%)$, sodium $(96.48 \%)$ and total organic carbon $(98.57 \%)$. At low pressure, the membrane's efficiency decreases. Also, high pressure can cause excessive energy consumption (Van der Bruggen and Vandecasteele 2003).

The purpose of this study is to investigate the independence or non-independence of the various elements' rejection, such as sodium, magnesium, potassium, calcium, sulfate, chloride, nitrate and EC in comparison with other existing elements in water as well as the determination of optimum pressure in this process.

\section{Materials and methods}

This research is an experimental study that investigates the desalination of regional groundwater in Qazvin province (Fig. 1) using a pilot nanofilter. The effect of nanofiltration on the rejection of major anions and major cations of water including sodium, potassium, calcium, magnesium, chloride, sulfate and electrical conductivity of water, as well as the effect of pressure on this process, was also investigated to determine the optimal pressure.

Currently, drinking water for this region is provided through the extraction of water from three deep wells as shown in Fig. 2.

\section{Design and pilot setup}

In this design, a low-pressure pump is used to supply the primary influent, a cartridge filter is used as a microfiber, a high-pressure pump is used to supply the raw water pressure to overcome the osmotic pressure, and at the end, a tank is used in which the membrane will be placed to split the flow of raw water into two streams of treated water and concentrate. In the final system, due to the fact that water cannot be supplied as a feed continuously, the system was set up in a batch mode in order to solve this problem by returning treated water and concentrated water into the tank. In this pilot setup, plate and frame module is used in which the membrane is placed inside it.

After the construction of the main frame, the tank, lowpressure pump, gauge, three-stage filter cartridge for placing the required types of microfiber or activated carbon, high-pressure piston pump with electromotor, flow meter for determining the influent to the membrane, and a pressurized tank with a gauge placed on it to measure the internal pressure are configured. At the end of the tank, there are two streams of treated and concentrated water which are pumped back into the tank by the tubes. On the concentrated stream, there is a butterfly valve installed so that the inlet pressure can be adjusted. In this project, a nanofilter membrane (FILMTEC-NF90-4040) was used and the effect of pressure on desalting efficiency as well as the permeation rate of nanofilter membrane at various pressures was evaluated. To carry out this project, sampling was done for wells $\mathrm{A}, \mathrm{B}$ and $\mathrm{C}$, which were the sources of drinking water for the assigned region. The schematic design of nanofiltration is shown in Fig. 3.

The nanofilter module consists of a thin polyamide membrane with a size of 4040 and an NF90 type. The membrane properties are shown in Table 1. 
Fig. 1 Location of sampling region, south of Qazvin plain $(50 \mathrm{~km}$ to the center of the province)

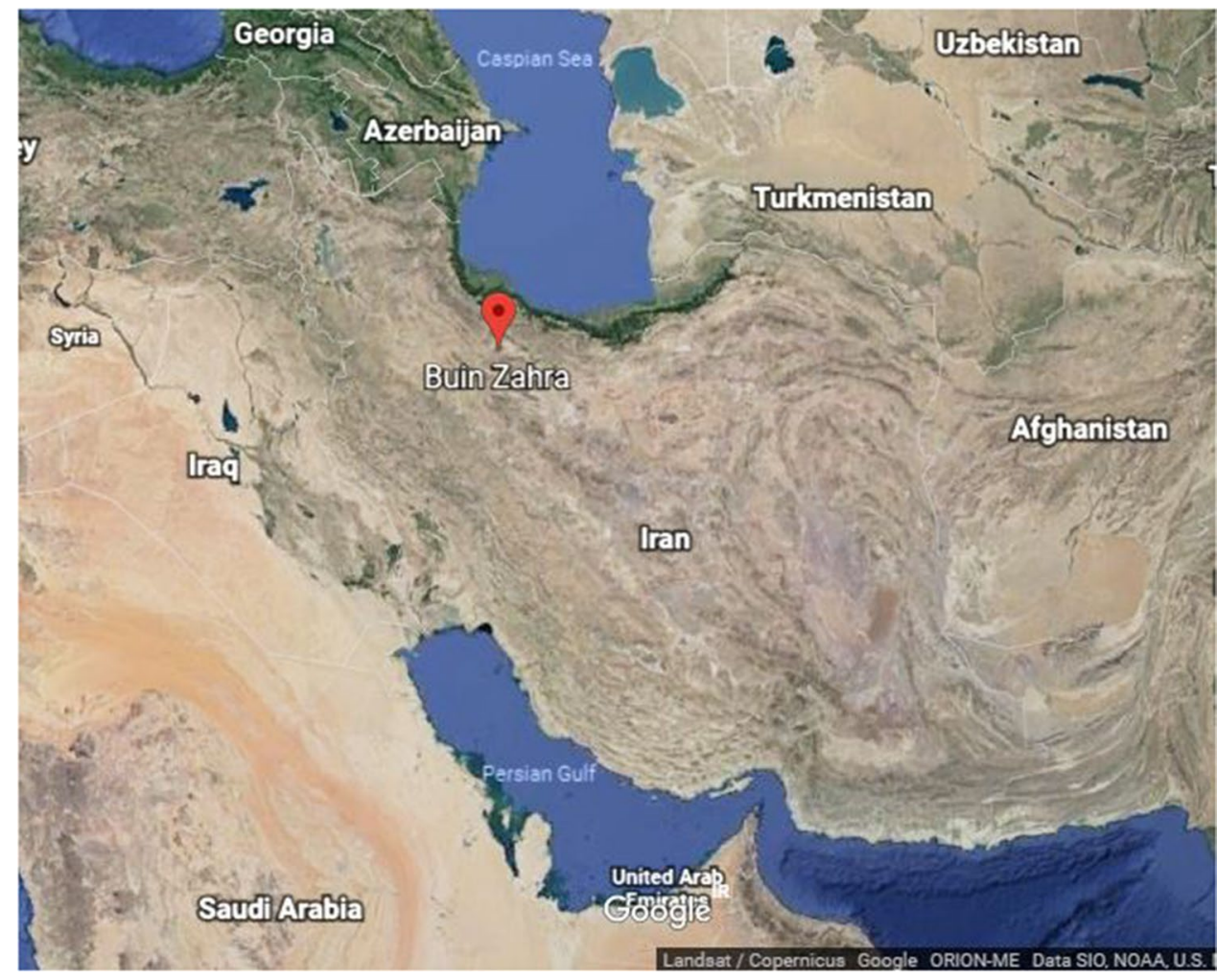

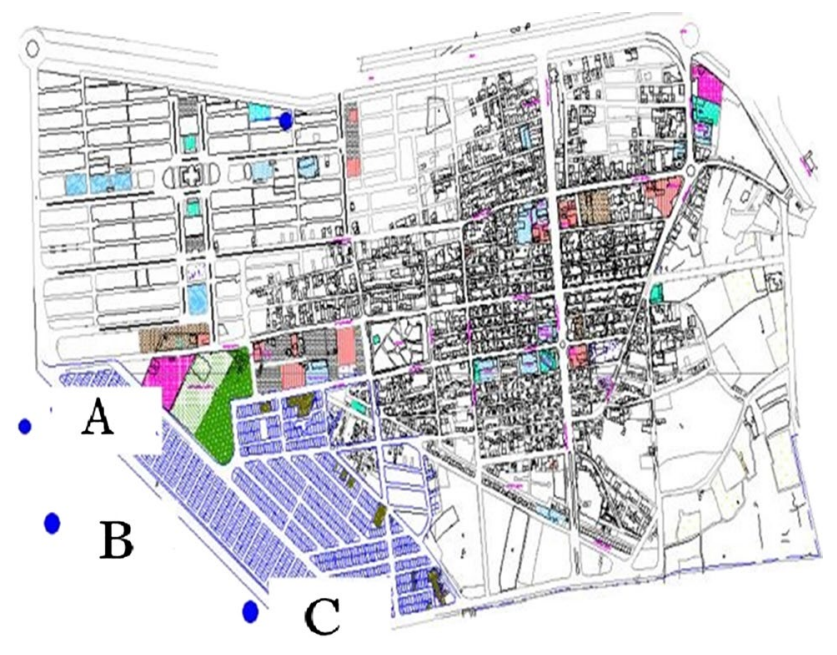

Fig. 2 Wells studied in this area

\section{Pre-treatment system}

This system includes a low-pressure pump that provides water pressure of about 3 bar, a microfiltration membrane that eliminates nanofilter membrane damage by removing fine particles, and an active carbon filter that removes free chlorine and organic matter from water and consequently increases the membrane's lifespan (Fig. 4).

In the temperature control system, a cooling unit includes aluminum pipes for cooling water flow, and the heating section made up of a $3-\mathrm{kW}$ power element is used to increase the temperature of the water. With an accurate electrical thermometer with a precision of $0.1{ }^{\circ} \mathrm{C}$, which by regulating its temperature, the electric power cutoff command is given to the element. The simultaneous operation of these two parts will stabilize the temperature of the raw water.

\section{Start-up and operation of nanofiltration pilot}

Initially, the water was prepared for testing at a volume of $40 \mathrm{~L}$ and was discharged into the pilot tank. Then, in order to prevent clogging of the membrane due to colloidal particles in the water, 1-, 5- and 10-micron microfilters were placed in the filter cartridge pool to remove the colloidal particles in a large amount. Hence, solution turbidity reached below 1 NTU. In our feed sample, the turbidity of the well water before the pre-treatment was 4.2 NTU. After placing the microfilters, and by cutting and placing a nanofilter piece in the pressure vessel, the pilot was set to operate.

At all stages of the experiment, plastic containers prepared for collecting water were first washed with distilled water and then washed again with treated water from the nanofilter at each stage. Then the effluent or treated water from the nanofilter membrane was collected in them. In each sampling, a volume of about $50 \mathrm{cc}$ of treated water was collected successively in three plastic containers to measure the content of total dissolved solids (TDS), and anions and cations in treated water. 
Fig. 3 Schematic view of the experimental nanofiltration mini pilot plant (Rao et al. 2012)

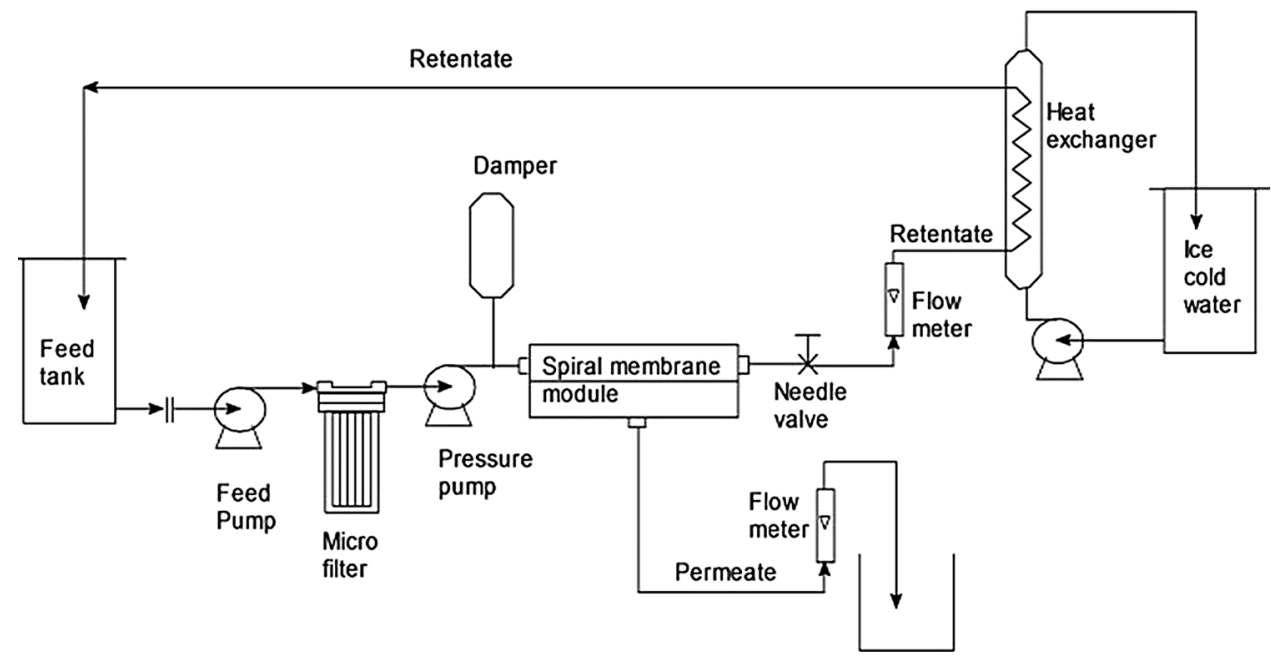

Table 1 Specifications of the membrane

\begin{tabular}{ll}
\hline Membrane type & $\begin{array}{l}\text { Polyamide thin-film composite } \\
\text { (TFC) }\end{array}$ \\
\hline Maximum operating temperature & $113{ }^{\circ} \mathrm{F}\left(45^{\circ} \mathrm{C}\right)$ \\
Maximum operating pressure & $600 \mathrm{psi}(41 \mathrm{bar})$ \\
Maximum feed flow rate & $70.0 \mathrm{gpm}\left(15.9 \mathrm{~m}^{3} / \mathrm{h}\right)$ \\
pH range, continuous operation & $2-11$ \\
Free chlorine tolerance & $<0.1 \mathrm{ppm}$ \\
Permeate flow rate & $\mathrm{MgSO} 4: 9500 \mathrm{GPD}\left(36 \mathrm{~m}^{3} / \mathrm{day}\right)$ \\
& $\mathrm{NaCl}: 7500 \mathrm{GPD}\left(28.4 \mathrm{~m}^{3} /\right.$ day $)$ \\
Stabilized salt rejection & $\mathrm{MgSO} 4:>97 \%$ \\
& $\mathrm{NaCl}: 85-95 \%$ \\
\hline
\end{tabular}

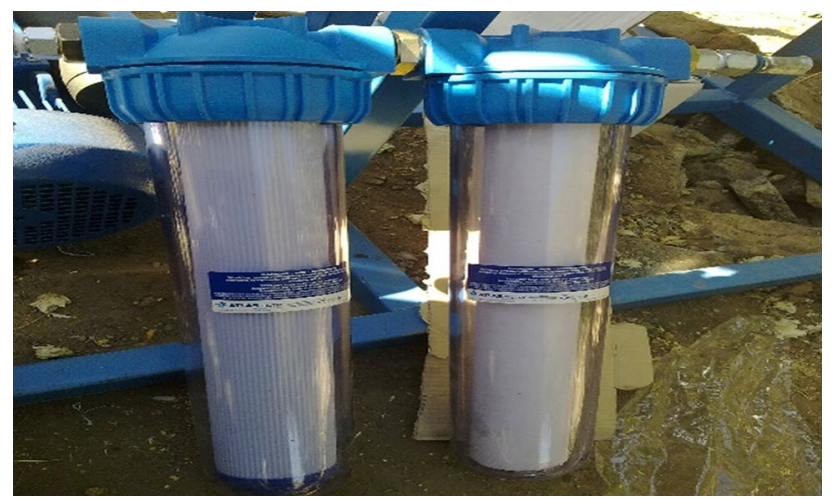

Fig. 4 Pre-treatment system

\section{Apparatus and methods of measurement}

The analysis of samples was investigated following the APHA standard (APHA et al. 2005). Electrical conductivity (EC) and total dissolved solids (TDS) were measured by a conductivity meter (JENWAY model 4320, UK). Chloride $\left(\mathrm{Cl}^{-}\right)$, sodium $\left(\mathrm{Na}^{+}\right)$, potassium $\left(\mathrm{K}^{+}\right)$, calcium $\left(\mathrm{Ca}^{2+}\right)$,
Table 2 Characteristics of raw water

\begin{tabular}{lccc}
\hline Parameters & \multicolumn{3}{l}{ Well } \\
\cline { 2 - 4 } & $\mathrm{A}$ & $\mathrm{B}$ & $\mathrm{C}$ \\
\hline Sodium $(\mathrm{mg} / \mathrm{L})$ & $215 \pm 25$ & $185 \pm 18$ & $188 \pm 21$ \\
Magnesium $(\mathrm{mg} / \mathrm{L})$ & $68 \pm 8$ & $48.8 \pm 9$ & $44.9 \pm 5$ \\
Potassium $(\mathrm{mg} / \mathrm{L})$ & $4.2 \pm 0.05$ & $4.55 \pm 0.7$ & $3.5 \pm 0.2$ \\
Calcium $(\mathrm{mg} / \mathrm{L})$ & $28.07 \pm 1.5$ & $28.2 \pm 0.9$ & $46.7 \pm 1.2$ \\
Sulfate $(\mathrm{mg} / \mathrm{L})$ & $350 \pm 28$ & $312 \pm 20$ & $235 \pm 18$ \\
Chloride $(\mathrm{mg} / \mathrm{L})$ & $160 \pm 17$ & $115 \pm 12$ & $75.1 \pm 14$ \\
Nitrate $(\mathrm{mg} / \mathrm{L})$ & $15.6 \pm 0.8$ & $12.8 \pm 0.5$ & $13.7 \pm 9.0$ \\
EC $(\mu \mathrm{S} / \mathrm{cm})$ & $328 \pm 32$ & $1359 \pm 450$ & $49.2 \pm 2.5$ \\
\hline
\end{tabular}

magnesium $\left(\mathrm{Mg}^{2+}\right)$, sulfate $\left(\mathrm{SO}_{4}{ }^{2-}\right)$ and nitrate $\left(\mathrm{NO}_{3}{ }^{-}\right)$were measured by a high-performance ion chromatography system (ICS3000, USA). The flow rate was about $2.5-5.2 \mathrm{ml} /$ min, and the system pressure was $25 \mathrm{MPa}$. A cationic column with the size of $4 \times 125 \mathrm{~mm}$ was used, the column body was made of steel, and a standard flow of $1 \mathrm{ml} / \mathrm{min}$ passed through it. In order to ensure the data reliability, all the samples were characterized with three replicates. The data in this study were recorded as the mean value \pm standard deviation. The characteristics of the raw water are shown in Table 2.

The maximum pressure and particle size were $35 \mathrm{MPa}$ and $7 \mu \mathrm{m}$, respectively. All measurements were carried out at room temperature, and all samples were filtered by a $0.44-\mu \mathrm{m}$ syringe filter before injection. For all samples, the injection was carried out at least three times. The data collection and operation of the system was performed by the 761 compact IC version 1.1 software.

In addition, to calculate the degradation efficiency of the parameters desired by the system, these parameters were read, after sampling the nanofilter-treated water and wastewater from the pilot tank. Accordingly, the following equation was used to determine the rejection: 
$R(\%)=\left(1-C_{\mathrm{p}} / C_{0}\right) \times 100 \quad($ Krieg, Modiseet et al. 2005)

where $R(\%), C_{0}$ and $C_{\mathrm{p}}$ are the rejection (\%), the content of the permeate $(\mathrm{mg} / \mathrm{L})$ and the content of the feed water $(\mathrm{mg} / \mathrm{L})$, respectively.

\section{Results and discussion}

The data were analyzed for the effect of independent and non-independent parameters on the quality of groundwater. The rejection rate of ions at various temperatures and pressures of 4, 8 and 12 bar for well $\mathrm{A}$ is depicted in Figs. 5, 6 and 7.

In comparison with various temperatures $\left(10-30{ }^{\circ} \mathrm{C}\right)$, $\mathrm{Mg}^{2+}$ and $\mathrm{No}^{3-}$ had the highest (100\%) and lowest (44\%) rejection rates at a pressure of 4 bar, respectively. In addition, $\mathrm{Na}^{+}$and $\mathrm{EC}$ are also in the range of rejection (93-95\%). As shown in Fig. 6, at a pressure of 8 bar, the rejection rate of $\mathrm{So}^{4-}, \mathrm{Na}^{+}, \mathrm{Ca}^{2+}, \mathrm{Mg}^{2+}, \mathrm{K}^{+}$and $\mathrm{EC}$ at all temperatures are higher than $92 \%$, while the rejection of $\mathrm{No}^{3-}$ and $\mathrm{Cl}^{-}$is less than $85 \%$ and $50 \%$, respectively. Additionally, as presented in Fig. 7, at a pressure of 12 bar, the rejection rate of $\mathrm{So}^{4-}$, $\mathrm{Na}^{+}, \mathrm{Ca}^{2+}, \mathrm{Mg}^{2+}, \mathrm{K}^{+}$and $\mathrm{EC}$ at all temperatures is higher than $90 \%$, while the rejection of $\mathrm{No}^{3-}$ and $\mathrm{Cl}^{-}$is approximately $80 \%$ and less than $40 \%$, respectively.

According to the diagrams (Figs. 5, 6, 7, 8, 9, 10, 11, 12 and 13), in case of anions, the highest degradation efficiency observed belongs to sulfate ions. Afterward, ion chloride is found, and its rejection rate is inversely proportional to its content in the solution. The lowest degradation efficiency is related to nitrate ion.

The rejection rate of ions at various temperatures and pressures of 4, 8 and 12 bar for well B is presented in Figs. 8, 9 and 10. Figure 8 shows that, at a pressure of 4 bar, the rejection values of $\mathrm{So}_{4}^{-}, \mathrm{Cl}^{-}$and $\mathrm{No}_{3}{ }^{-}$first decrease with increasing temperature and then increase. Likewise, at temperatures $10{ }^{\circ} \mathrm{C}$ and $30{ }^{\circ} \mathrm{C}$, the maximum rejection values of $\mathrm{Ca}^{2+}$ and $\mathrm{Mg}^{2+}$ for this well are $100 \%$. As presented in
Fig. 5 Rejection rate of ions versus temperature (pressure: 4 bar)

Fig. 6 Rejection rate of ions versus temperature (pressure: 8 bar)
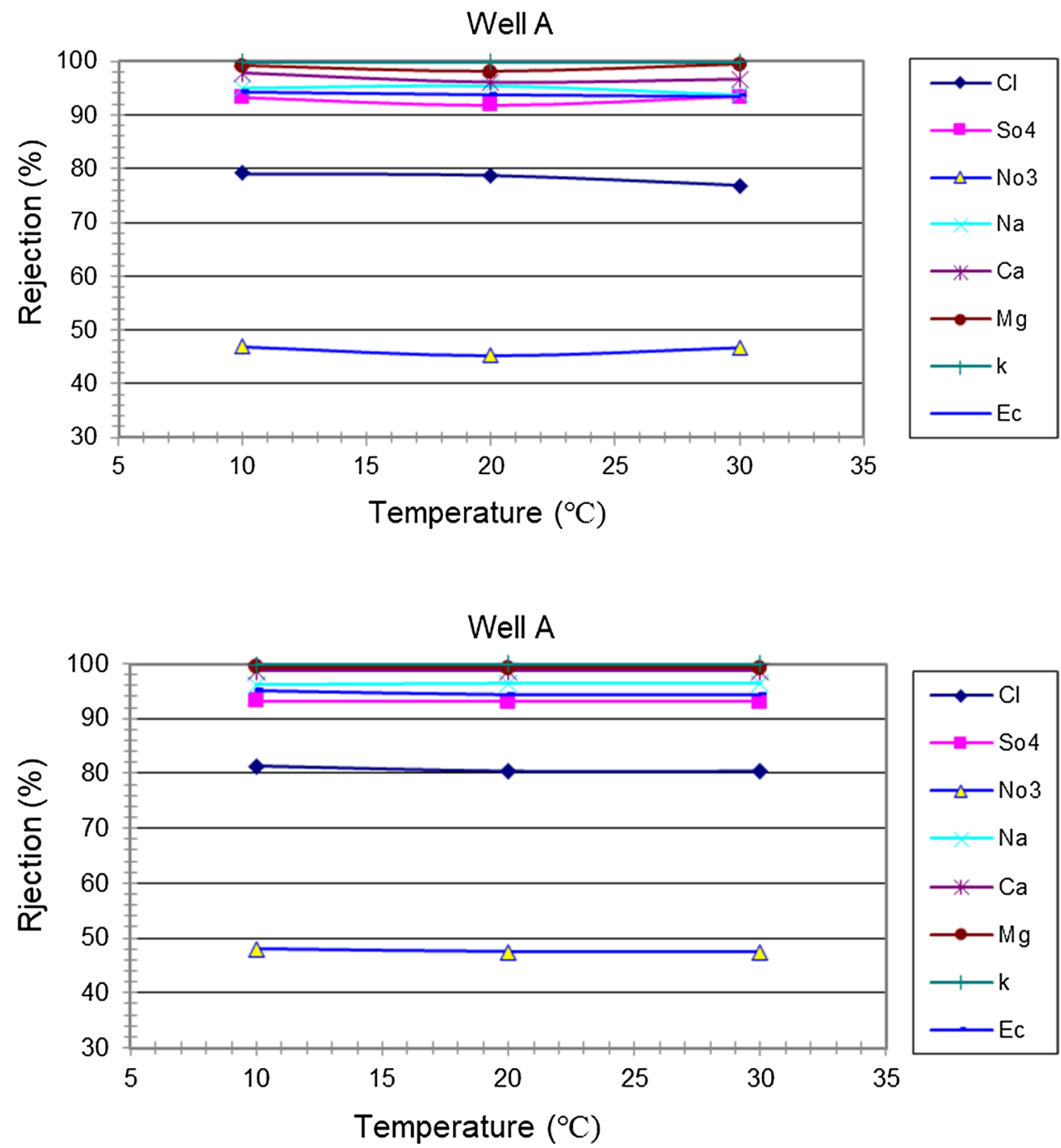
Fig. 7 Rejection rate of ions versus temperature (pressure: 12 bar)
Fig. 8 Rejection rate of ions versus temperature (pressure: 4 bar)
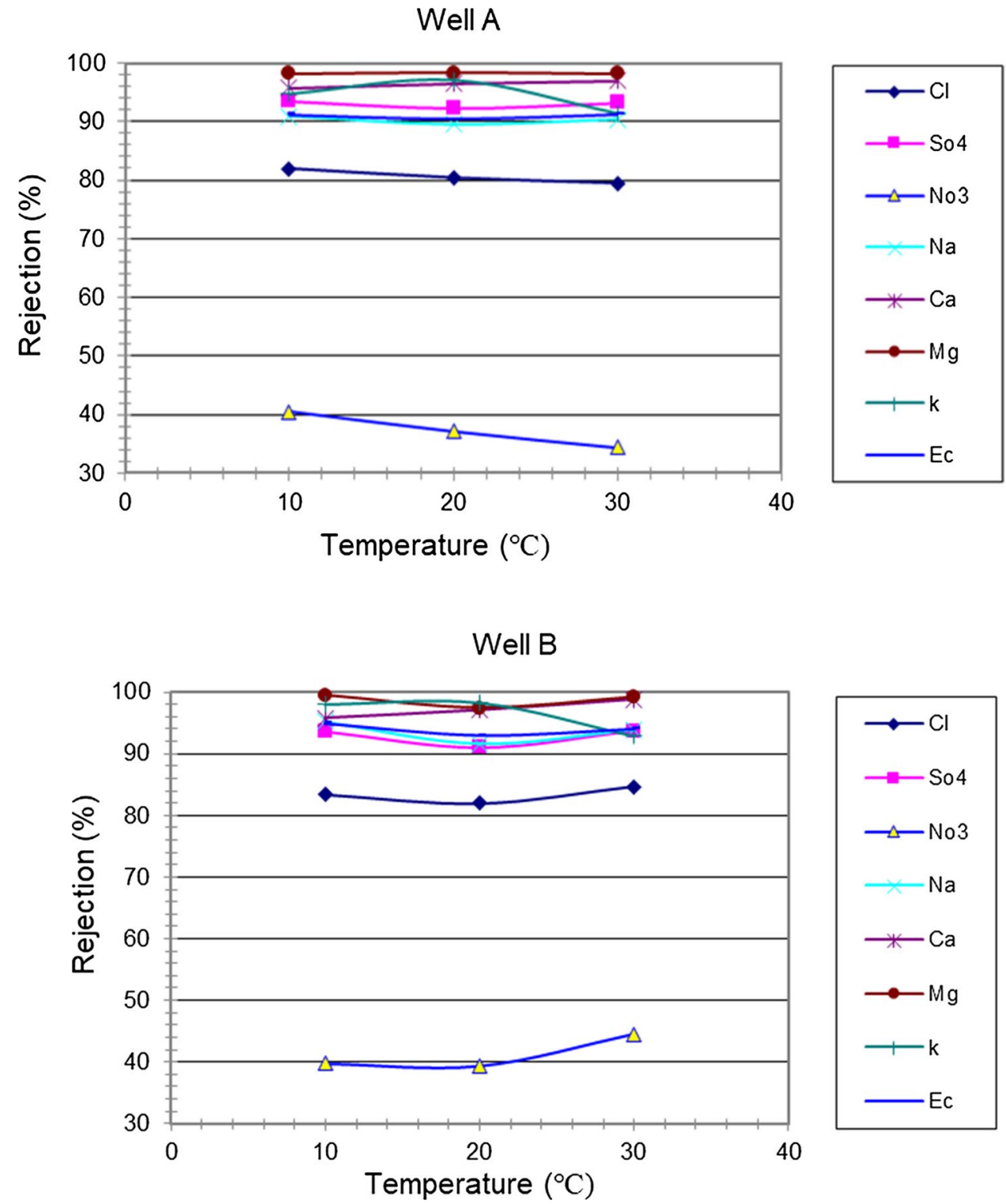

Fig. 9, at a pressure of 8 bar, the rejection values of $\mathrm{Cl}^{-}$, $\mathrm{Ca}^{2+}$ and $\mathrm{Mg}^{2+}$ show a decreasing trend with increasing temperature. In this way, $\mathrm{Cl}^{-}\left(85-79 \%\left(, \mathrm{Ca}^{2+}(99-96 \%)\right.\right.$ and $\mathrm{Mg}^{2+}(100-96 \%)$ have a downward trend. Figure 10 proves that the current existing process removes $\mathrm{Ca}^{2+}$ and $\mathrm{Mg}^{2+}$ well. Over $99 \%$ of both of these were removed from groundwater in the current process at $30{ }^{\circ} \mathrm{C}$.

The comparison between $\% R$ of $\mathrm{Ca}^{2+}$ assessed in this work and those achieved in the literature shows that the performance of NF90-4040 nanofiltration to retentive $\mathrm{Ca}^{2+}$ is better than NanoMax50 (Ghizellaoui et al. 2005) (50\% \%R of $\mathrm{Ca}^{2+}$ ) and NF200B-400 (Costa and De Pinho 2006) (64\%). The ability of this nanofiltration to retentive $\mathrm{Mg}^{2+}(\% R$ is 95\%) is better than NF200B (Gorenflo et al. 2003) (greater than $86 \%$ ). The rejection rate of ions at various temperatures and pressures of 4,8 and 12 bar for well $\mathrm{C}$ is presented in
Figs. 11, 12 and 13. As can be seen in Fig. 11, at a pressure of $4 \mathrm{bar}$, with increasing temperature, the rejection rates of $\mathrm{Cl}^{-}, \mathrm{So}_{4}^{-}, \mathrm{Na}^{+}, \mathrm{Mg}^{2+}$ and $\mathrm{EC}$ first decrease and then increase slightly, while the rejection rate of $\mathrm{K}^{+}$is the vice versa. Furthermore, Fig. 12 shows a similar trend for $\mathrm{K}^{+}, \mathrm{Na}^{+}$and EC. The maximum rejection for $\mathrm{Mg}^{2+}, \mathrm{Ca}^{2+}, \mathrm{Na}^{+}$and EC is $100 \%$ and $99.5 \%, 98.5 \%$ and $96 \%$, respectively, and occurs at a temperature of $10{ }^{\circ} \mathrm{C}$. At a pressure of $12 \mathrm{bar}$, the rejection rate of all ions is ascending as temperature increases, except for $\mathrm{No}_{3}{ }^{-}$, which is the vice versa. Likewise, the highest decrease in the rejection rate with increasing temperature is about $33 \%$ for $\mathrm{No}_{3}{ }^{-}$.

The results in Figs. 5, 6, 7, 8, 9, 10, 11, 12 and 13 show that the rejection rate of bivalent ions (calcium and magnesium) is higher than that of the monovalent ions (sodium and potassium). The reason for this is the pressure and 
Fig. 9 Rejection rate of ions versus temperature (pressure: 8 bar)
Fig. 10 Rejection rate of ions versus temperature (pressure: 12 bar)
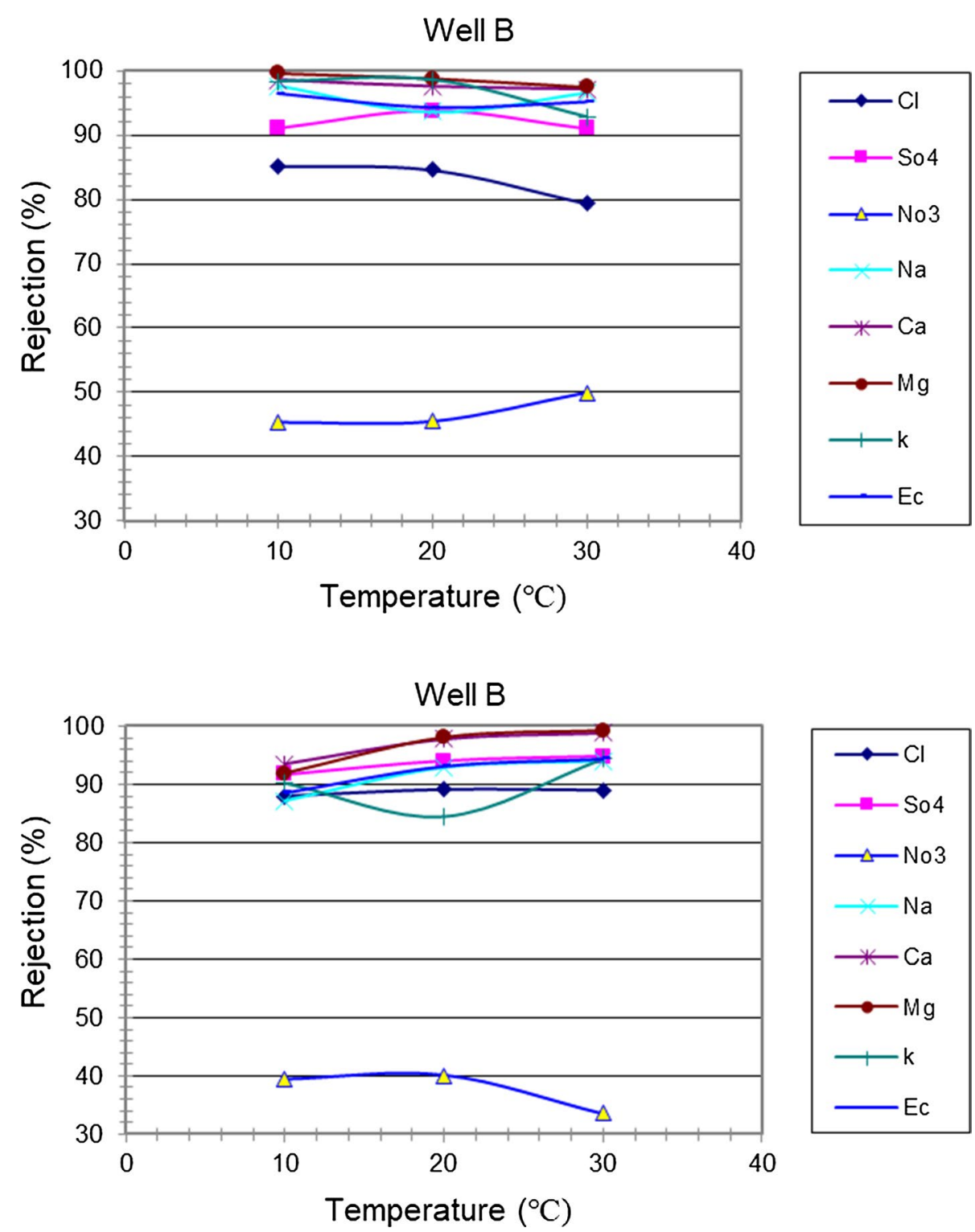

content of higher suppository solids increase rejection, while rejection rates are somewhat lower in higher ionic strength (Visvanathan et al. 1998). The content of calcium rejection was higher than that of magnesium, which can be evaluated based on a smaller magnesium ion radius which varies from 0.44 to 0.41 Angstrom. In this way, the higher solubility energy of magnesium ion resulted in an increase in its degradation efficiency. Therefore, in case of comparing the degradation efficiency of the cations, the following series can be shown: $\mathrm{Mg}>\mathrm{Ca}>\mathrm{K}>\mathrm{Na}$.

The results of this study stated that increasing the temperature and increasing the dissolution of salts in solution result in increasing soluble cations content and cations neutralize the surface charge of the membrane, and this, in turn, increases the passage of other ions, and less nitrate is removed. The results of Kang et al.'s (2009) study in Korea in 2009 for the rejection of nitrate are consistent with the results of this study. On the other hand, in case of the higher electrical capacitance anions (such as sulfate), the highest degradation efficiency was observed, which causes a loss of electric charge balance on both sides of the membrane. In addition, the lowest degradation efficiency was observed for the rejection of nitrate ions. Temperature rises in all cases, the feed reduces the percentage of ion, but its effect on $\mathrm{No}_{3}{ }^{-}$, $\mathrm{So}_{4}^{-}$and $\mathrm{Cl}^{-}$is higher than on other ions. Several factors can be considered in terms of ion rejection by increasing the temperature.

As far as we know, on the one hand, when the temperature ascends, the viscosity decreases and the penetration coefficient of the solution component increases. On the other hand, the increase in temperature causes an increase in the diameter of the membrane pores (especially the 
Fig. 11 Rejection rate of ions versus temperature (pressure: 4 bar)

Fig. 12 Rejection rate of ions versus temperature (pressure: 8 bar)
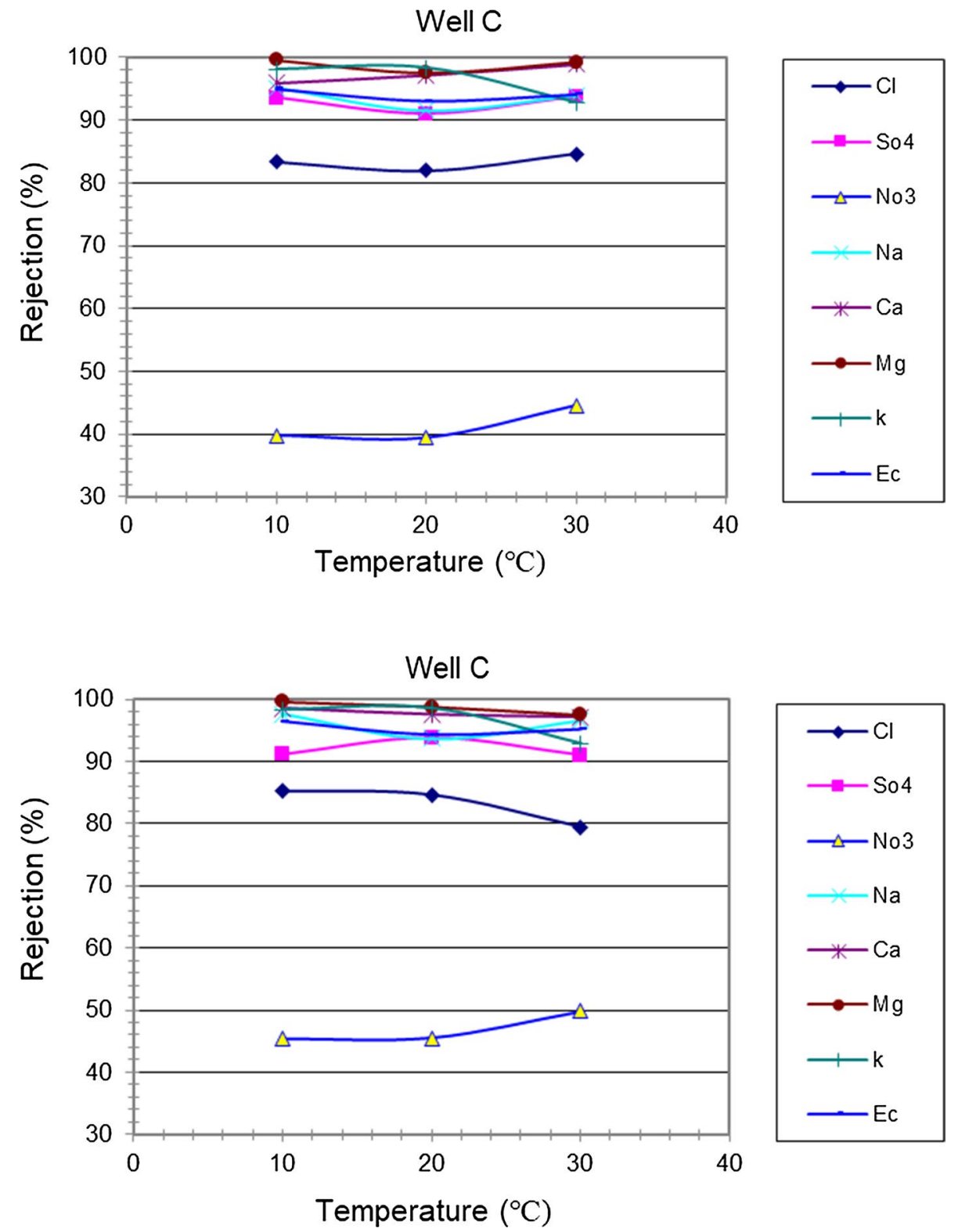

polymer membranes) and thus the membrane's resistance to the passage of the solution decreases; thereby, the flux of the component increases. Increasing the pressure usually results in increased ion rejection in the membrane. However, the effect of pressure on ion removal in all membranes may not be significant. Researchers believe that by increasing the pressure and water flux, more ions are transferred to the surface of the membrane. As the permeate flux increases, concentration polarization also intensifies and this will reduce ion rejection. In another study, the rejection rate for bivalent ions of above $90 \%$ was perceived, and with increasing pressure, the rejection rates were lowered with a slope than monovalent ions was found. Studies also showed that high rejection rates for bivalent ions such as magnesium $(>95 \%)$ and sulfate
(>98\%) were reported. They reported that the rejection of monovalent ions was less than bivalent ions due to the lower molecular weight of these ions (Seidel et al. 2001; Wu et al. 2004; Fersi and Dhahbi 2008; Song et al. 2016).

The results revealed that the rejection of bivalent ions, such as calcium, magnesium and sulfate, does not depend on the ionic quality of water, and it is done a lot. Yet, the rejection of monovalent ions such as nitrates is significantly affected by the influent water quality which consequently impacts on the performance of this system. By increasing the content of bivalent ions such as sulfate anions and increasing the ratio of monovalent cations to bivalent ions, the content of nitrate rejection decreased significantly. In other words, increasing the hardness and reducing the content of sulfate increases the content of nitrate rejection. 
Fig. 13 Rejection rate of ions versus temperature (pressure: 12 bar)

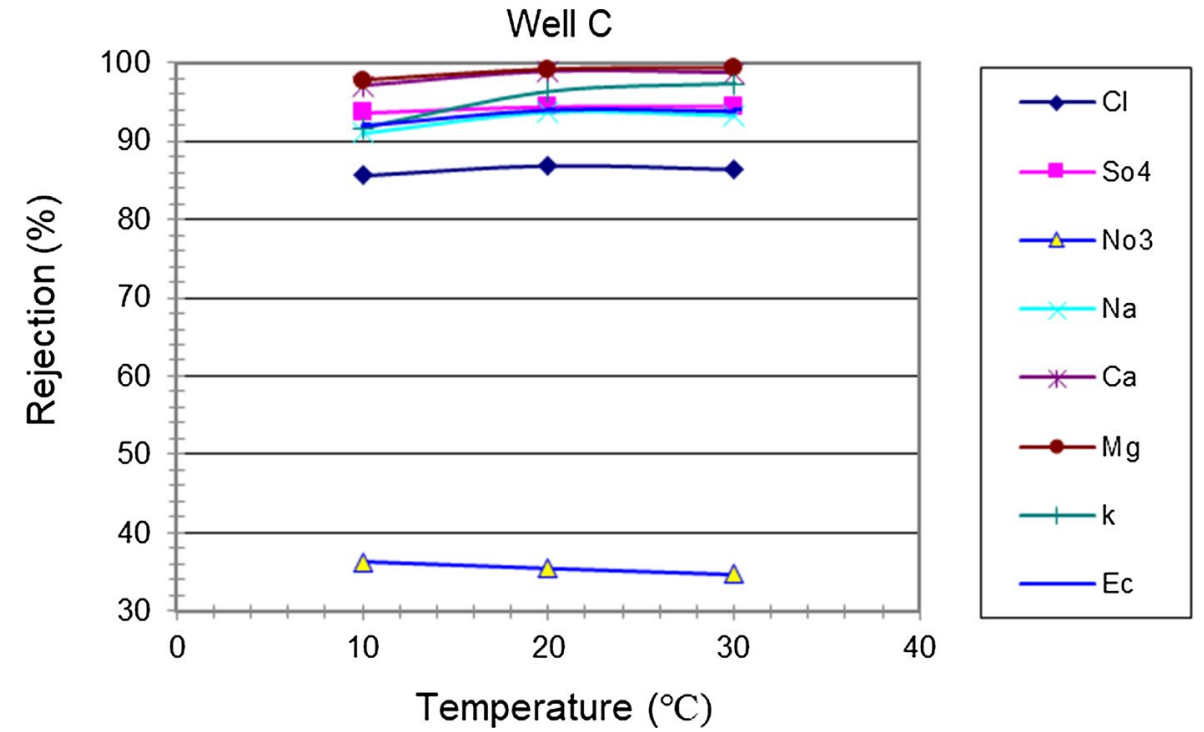

As shown in Figs. 5, 6, 7, 8, 9, 10, 11, 12 and 13, most ions, with the exception of nitrate, have a degradation efficiency higher than $80 \%$, which indicates the proper functioning of the nanofiltration membrane in removing cations, anions and electrical conductivity. The content of permeation in a nanofilter is higher than the theoretical value, and the operating pressure is less than that obtained from the Hoff vantage equation. Based on Hoffman's relationship, osmotic pressure for saline and brackish water is calculated as follows and in fact, is the minimum pressure for osmotic permeability. However, according to the experiments, permeability in the nanofilter has started at a pressure of 8 bar, which is due to the electrical effects of the membrane.

$\pi=R T \cdot \Delta C$

It was also observed that increasing the influent solution pressure increased the water flux passing through the membrane and the effective pressure of water passing through the membrane was the main determinant of the amount of water infiltrated. Moreover, the higher the flux pressure, the higher the penetrated water through membrane. According to the results observed in the studied cations, the percentage of sodium ion rejection is low; however, the difference is not that sharp. This is due to the high sodium ion diffusion coefficient as compared to other cations, and it evokes the Nernst-Planck equation in mind. The rejection rate is a direct function of membrane material. In the research carried out by Mika et al. (2001) higher contents are tested, and with a more precise investigation of membrane material, it is concluded that the difference in rejection rate was significant in all types of membrane. In these two studies, it has been shown that there is a higher rejection rate in bivalent ions with more charges, which can be due to the electrical effects of the nanofilter membrane. Nanofiltration has recently been very much considered as a new technique for softening of super-hard waters.

\section{Conclusions}

The nanofiltration study presented herein on groundwater samples indicates that the maximum rejection occurs at a pressure of $12 \mathrm{bar}$, for well $\mathrm{C}$, and the corresponding values for $\mathrm{Ca}^{2+}$ and $\mathrm{Mg}^{2+}$ are in the range of $97-100 \%$. On the other hand, the minimum rejection occurs at a pressure of 12 bar and the temperature of $30^{\circ} \mathrm{C}$, for well $\mathrm{B}$, and the corresponding values are approximately $32 \%$. The results show that the presence of high magnesium ion is very effective in reducing sodium ion discharge and at the same time, the rejection rate of ions does not always follow the Van't Hoff series which requires more extensive theoretical and practical studies; thereupon, the ion rejection rate in the nanofiltration membrane is not independent of others. Treatment of groundwater with the combination of nanofiltration and forward osmosis process will be investigated. In addition, the mechanism of the effect of element rejection on each other would be one of the major interests in our future work.

Open Access This article is distributed under the terms of the Creative Commons Attribution 4.0 International License (http://creativeco mmons.org/licenses/by/4.0/), which permits unrestricted use, distribution, and reproduction in any medium, provided you give appropriate credit to the original author(s) and the source, provide a link to the Creative Commons license, and indicate if changes were made. 


\section{References}

Alkhatim H et al (1998) Treatment of whey effluents from dairy industries by nanofiltration membranes. Desalination 119(1-3):177-183

AlTaee A, Sharif AO (2011) Alternative design to dual stage NF seawater desalination using high rejection brackish water membranes. Desalination 273(2-3):391-397

APHA, AWWA, WPCF (2005) Standard methods for the examination of waters and waste waters, 21st edn. American Public Health Association (APHA), Washington

Aroji N et al (2016) Nano-filtration system efficiency in urban water treatment and removal of pollutants in Molasani water treatment plant. Irrig Sci Eng 39(4):201-212

Chakrabortty S et al (2013) Removal of fluoride from contaminated groundwater by cross flow nanofiltration: transport modeling and economic evaluation. Desalination 313:115-124

Cominelli E et al (2009) Water: the invisible problem: access to fresh water is considered to be a universal and free human right, but dwindling resources and a burgeoning population are increasing its economic value. EMBO Rep 10(7):671-676

Costa AR, De Pinho MN (2006) Performance and cost estimation of nanofiltration for surface water treatment in drinking water production. Desalination 196(1-3):55-65

Dach H (2008) Comparison of nanofiltration and reverse osmosis processes for a selective desalination of brackish water feeds. Université d'Angers, Angers

Emamjomeh MM et al (2018) Effect of temperature and pressure on removal of fluoride from groundwater using nanofiltration. J Mazandaran Univ Med Sci 27(156):166-176

Fersi C, Dhahbi M (2008) Treatment of textile plant effluent by ultrafiltration and/or nanofiltration for water reuse. Desalination 222(1-3):263-271

Galanakis CM et al (2012) Nanofiltration of brackish groundwater by using a polypiperazine membrane. Desalination 286:277-284

Gehrke I et al (2015) Innovations in nanotechnology for water treatment. Nanotechnol Sci Appl 8:1-17

Ghizellaoui S et al (2005) Use of nanofiltration for partial softening of very hard water. Desalination 179(1-3):315-322

Gorenflo A et al (2003) Nanofiltration of a German groundwater of high hardness and NOM content: performance and costs. Desalination 151(3):253-265

Gray NF (2008) Drinking water quality: problems and solutions. Cambridge University Press, Cambridge

Honarbakhsh A et al (2019) GIS-based assessment of groundwater quality for drinking purpose in northern part of Fars province, Marvdasht. J Water Supply Res Technol Aqua. https://doi. org/10.2166/aqua.2019.119

Jury WA, Vaux HJ Jr (2007) The emerging global water crisis: managing scarcity and conflict between water users. Adv Agron 95:1-76

Kang M et al (2009) Nitrate by nanofiltrations in very small drinking water systems. World Appl Sci J 5:41-45

Krieg $\mathrm{H}$ et al (2005) Salt rejection in nanofiltration for single and binary salt mixtures in view of sulphate removal. Desalination 171(2):205-215

Mayer T et al (2010) Nanotechnology applications to desalination: a report for the joint water reuse \& desalination task force. Technical report. Sandia National Laboratories, Albuquerque
Mika AM et al (2001) Ultra-low-pressure water softening with porefilled membranes. Desalination 140(3):265-275

Mohammadi P et al (2018) Studying quality of drinking water and determining sustainable indicators for water resources of villages of Harsin Town of Iran. Int J Health Life Sci 4(2):e83508

Mortazavi B, Mousavi G (2012) Performance of nanofiltration for dissolved iron removal from ground water. J Health 3(1):41-48

Najafpoor AA et al (2014) Study on the adsorption isotherms of chromium (VI) by means of carbon nano tubes from aqueous solutions. Environ Health Eng Manag J 1(1):1-5

Nicolaisen B (2003) Developments in membrane technology for water treatment. Desalination 153(1-3):355-360

Pantelides ST (2013) The physics of $\mathrm{SiO}_{2}$ and its interfaces. In: Proceedings of the international topical conference on the physics of $\mathrm{SiO}_{2}$ and its interfaces held at the IBM Thomas J. Waston Research Center, Yorktown Heights, New York, March 22-24, 1978, Elsevier

Rao AB et al (2012) Simple extraction and membrane purification process in isolation of steviosides with improved organoleptic activity. Adv Biosci Biotechnol 3(04):327

Seidel A et al (2001) Role of charge (Donnan) exclusion in removal of arsenic from water by a negatively charged porous nanofiltration membrane. Environ Eng Sci 18(2):105-113

Song Y et al (2016) Analysis of nanofiltration membrane performance during softening process of simulated brackish groundwater. Desalination 399:159-164

Talaeipour $\mathrm{M}$ et al (2017) An investigation of desalination by nanofiltration, reverse osmosis and integrated (hybrid NF/RO) membranes employed in brackish water treatment. J Environ Health Sci Eng 15:18

Van der Bruggen B, Vandecasteele C (2003) Removal of pollutants from surface water and groundwater by nanofiltration: overview of possible applications in the drinking water industry. Environ Pollut 122(3):435-445

Vaseghi $G$ et al (2016) Characterization of reverse osmosis and nanofiltration membranes: effects of operating conditions and specific ion rejection. Desalin Water Treat 57(50):23461-23472

Visvanathan C et al (1998) Removal of THMP by nanofiltration: effects of interference parameters. Water Res 32(12):3527-3538

WHO (World Health Organisation) (2011) Guidelines for drinkingwater quality. WHO chronicle 38(4):104-108

Wimalawansa SJ (2013) Purification of contaminated water with reverse osmosis: effective solution of providing clean water for human needs in developing countries. J Emerg Technol Adv Eng 3(12):75-89

Wu M et al (2004) Effect of operating variables on rejection of indium using nanofiltration membranes. J Membr Sci 240(1-2):105-111

Xiao P et al (2012) Investigation of organic foulants behavior on hollow-fiber UF membranes in a drinking water treatment plant. Sep Purif Technol 95:109-117

Publisher's Note Springer Nature remains neutral with regard to jurisdictional claims in published maps and institutional affiliations. 